\title{
AXL is a key factor for cell plasticity and promotes metastasis in pancreatic cancer
}

Wenting Du1,2,\#, Huocong Huang ${ }^{1}$, Zhaoning Wang ${ }^{3}$, Jason E. Toombs ${ }^{1}$, Natalie Z. Phinney ${ }^{1,2}$, Yuqing Zhang ${ }^{1,2}$, Muhammad S. Beg ${ }^{4}$, Thomas M. Wilkie ${ }^{5}$ James B. Lorens $^{6}$ and Rolf A. Brekken $1,2,7, *$

${ }^{1}$ Department of Surgery and Hamon Center for Therapeutic Oncology Research, ${ }^{2}$ Cancer Biology Graduate Program, ${ }^{3}$ Department of Molecular Biology, ${ }^{4}$ Department of Internal Medicine, ${ }^{7}$ Department of Pharmacology, University of Texas Southwestern Medical Center, Dallas, TX

${ }^{6}$ Department of Biomedicine, Centre for Cancer Biomarkers, Norwegian Centre of Excellence, University of Bergen, Bergen, Norway

\section{\#Corresponding author:}

Rolf A. Brekken, PhD

Hamon Center for Therapeutic Oncology Research

UT Southwestern

6000 Harry Hines Blvd.

Dallas, TX 75390-8593

Tel: 214.648.5151; Fax: 214.648.4940

rolf.brekken@utsouthwestern.edu

\#Current Address:

Department of Surgery

University of Michigan

1500 E. Medical Center Dr.

Cancer Center 6110

Ann Arbor, MI 48109

Number of figures: 4 Main Figures, 6 Supplemental Figures 


\begin{abstract}
Pancreatic ductal adenocarcinoma (PDA), a leading cause of cancer-related death in the US, has a high metastatic rate and is associated with persistent immune suppression. AXL, a member of the TAM (TYRO3, AXL, MERTK) receptor tyrosine kinase family, has been identified as a driver of metastasis and immune suppression in multiple cancer types. Here we use single cell RNA sequencing to reveal that $A X L$ is expressed highly in tumor cells that have a mesenchymal-like phenotype and that AXL expression correlates with classic markers of mesenchymal tumor cells. We demonstrate that $A X L$-deficiency extends survival, reduces primary and metastatic burden and enhances sensitivity to gemcitabine in an autochthonous model of PDA. PDA in AXL-deficient mice displayed a more differentiated histology, higher nucleoside transporter expression and a more active immune microenvironment compared to PDA in wild-type mice. Finally, we demonstrate that AXL-positive mesenchymal tumor cells are critical for PDA progression and metastasis, emphasizing the potential of $A X L$ as a therapeutic target for PDA patients.
\end{abstract}




\section{Introduction}

Pancreatic ductal adenocarcinoma (PDA) is an aggressive cancer that has seen limited improvement in overall survival in the past 30 years (1). More than $80 \%$ of the patients are diagnosed at a late stage and as a result are not candidates for curative intent surgery (1). Thus, systemic chemotherapy is the mainstay of treatment. Current regimens, (5-fluorouracil or gemcitabine-based) offer only incremental prolongation of survival. Tumor cell intrinsic and acquired resistance to standard therapy underlies the poor response to systemic therapy (2). Tumor cell epithelial plasticity is a major contributor to PDA resistance to therapy.

There is a strong association between mesenchymal cancer cells and therapy resistance in multiple types of cancers (3-7). Tumor cells with a mesenchymal-like phenotype have a distinct gene expression signature, which often includes AXL $(4,8)$. AXL is a member of the TAM (TYRO3, AXL, MERTK) receptor tyrosine kinase family that binds to growth arrest-specific gene 6 (GAS6). AXL via GAS6 activation and via non-ligand-dependent mechanisms (9) mediates basic cell biological processes including cell migration and survival (10). Consistent with gene expression profiling studies, AXL expression is associated with therapy-resistance and metastasis in a variety of cancers, including NSCLC, breast cancer and PDA (11-20). AXL is also expressed by immune cells where it functions in efferocytosis, the clearance of apoptotic cells. This occurs in a GAS6dependent manner. GAS6 contains a y-carboxylation (Gla) domain that interacts with phosphatidylserine exposed on apoptotic cells. Thus, GAS6 serves as a bridging protein that results in the engulfment of apoptotic cells via AXL (or MERTK) activation $(21,22)$. Activation of AXL on immune cells in this manner also has immune regulatory effects (23-27). 
In PDA, high AXL expression is detected in $\sim 70 \%$ of patients and is associated with distant metastasis and worse survival $(28,29)$. Our lab previously investigated different pharmacologic strategies to inhibit $A X L$ activity in PDA $(30,31)$. We found that inhibition of vitamin K-dependent Y-carboxylation of Gla domain of GAS6 with warfarin suppressed metastasis of preclinical models of PDA in a tumor cell AXL-dependent manner (31), that warfarin use was associated with improved outcome in PDA patients (32) and that warfarin use is associated with reduced incidence of multiple cancer types, including pancreatic cancer (33). We also demonstrated the efficacy of a selective small molecular inhibitor of AXL, bemcentinib (BGB324) in combination with gemcitabine in multiple mouse models of PDA. We found that BGB324 drove epithelial differentiation, induced an immune-stimulatory environment and improved gemcitabine efficacy in vivo (30). However, the distribution of $A X L$ expression on different cells within PDA microenvironment and their contribution to PDA progression have not been investigated. Here we use single cell RNA sequencing (scRNA-Seq) to identify AXL-positive cell populations in genetically engineered mouse models (GEMMs) of PDA. We demonstrate the effect of AXL deletion on these AXL-positive populations, as well as PDA progression, metastasis and chemoresistance. Lastly, we show that AXL-positive tumor cells are critical for PDA progression. Our findings bolster the preclinical rationale for pharmacologic inhibition of AXL in PDA patients. 


\section{Results}

AXL is expressed in mesenchymal PDA tumor cells

We and others have shown that multiple cell types in the tumor microenvironment can express AXL $(9,10)$. To determine which cell populations in GEMMs of PDA are AXL positive, we analyzed scRNA-Seq data (34) with tumors harvested from early and late stage of KIC (Kras ${ }^{L S L-G 12 D /+}$, Ink4a/Arflox/lox, Ptf1 $\left.a^{C r e /+}\right)$ and late stage KPfC (Kras $\left.{ }^{L S L-G 12 D /+}, \operatorname{Trp5} 3^{\text {lox/lox }}, P d x^{C r e /+}\right)$ mice. tSNE plots of $A x I$ expression for each cell population in $K I C$ and $K P f C$ tumors are shown in Supplementary Figure 1. $A x l$ expression is highlighted in red for each model. Violin plots show that $A x l$ is expressed highly in advanced KIC (Fig. 1A) and is expressed by mesenchymal cancer cells, fibroblasts and macrophages in each GEMM (Fig. 1B). To confirm the scRNA-seq data, tumor tissues from $A x^{L a c z /+} K I C$ mice were evaluated for co-localization of $\beta$-galactosidase (identifying AXL expression, red) and PDA cell marker SOX9, fibroblast marker PDGFRa and aSMA, macrophage marker F4/80, epithelial marker E-cadherin and mesenchymal marker Vimentin. Double-positive cells were found using each of the markers except E-cadherin (Fig. 1C).

Gene clusters from AXL-positive cell populations were subjected to pathway and Gene Ontology (GO) analysis. The most highly expressed genes in AXL-positive cancer cells were associated with focal adhesion pathway, MAPK cascade, PI3K/AKT signaling, ECM-receptor interaction, and NF-KB signaling as well as functions that were regulated by these signaling pathways including wound healing, cell migration, cell adhesion, cell senescence, cell growth, epithelial to mesenchymal transition (EMT), and response to drug (Supplementary Fig. 2). Axl expression correlated with mesenchymal markers and negatively correlated with epithelial marker expression in cancer cell clusters in each GEMM (Fig. 1D), highlighting that AXL is associated with EMT in PDA tumor cells. In AXL-positive fibroblasts, the most highly expressed genes were involved in 
fibril organization $\left(p=4.07 \times 10^{-18}\right)$, extracellular matrix organization $\left(p=2.55 \times 10^{-15}\right)$ and collagen formation $\left(p=8.96 \times 10^{-13}\right)$. Whereas in AXL-positive macrophages, the most highly expressed genes were the associated with antigen processing and presentation $\left(p=1.05 \times 10^{-11}\right)$.

AXL deficiency prolongs survival, inhibits metastasis and EMT, and improves gemcitabine efficacy in a GEMM of PDA

To demonstrate the function of AXL in PDA progression, AxlLacZ/LacZ mice (lacZ gene was inserted

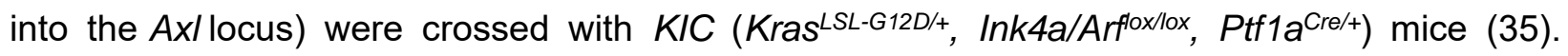
Global depletion of $A X L$ in $K I C$ mice $(n=26)$ led to a 10-day longer median survival (68 days, $\mathrm{p}<0.0001)$ compared to wild-type (WT) KIC (58 days, $\mathrm{n}=21)$ animals (Fig. 2A). Ax/Lacz/Lacz KIC mice had smaller primary tumors and fewer liver micrometastases (Fig. 2A). Further analysis of tumor tissue from $W T$ and $A x^{\text {LacZ/LacZ } K I C}$ mice showed that global AXL depletion did not affect cell proliferation (Ki67) or cell apoptosis (cleaved-caspase3, CC3, Supplementary Fig. 3). However, hematoxylin and eosin (H\&E) and EMT marker staining showed that AXL deficiency resulted in a less advanced, and more differentiated histology (increased E-cadherin and decreased Vimentin) (Fig. 2B). Global depletion of AXL also led to reduced aSMA expression by cancer associated fibroblasts (CAFs) indicative of reduced myCAFs (34) in the absence of AXL (Fig. 2B). In contrast, PDGFRa and CDH11, other markers of CAFs, and CD31, a marker of microvessel density, were not affected significantly by AXL deficiency (Supplementary Fig. 3).

EMT is associated with chemoresistance $(5,6)$. EMT can reduce the expression of nucleoside transporters, which limits the entry of chemotherapeutics into cancer cells (5). Given the more differentiated phenotype of $A X L$-deficient KIC tumors we stained $W T$ and $A X L$-deficient tumors for expression of equilibrative nucleoside transporter 1 (ENT1). Consistent with expectations, we 
found a dramatic increase of ENT1 protein expression in AxlLacZ/LacZ KIC compared to WT KIC animals ( $p=0.0209$, Fig. 2B). Based on this result, we hypothesized that $A x / L a c Z / L a c Z ~ K I C$ mice would be more sensitive to chemotherapy (gemcitabine). To test this, WT KIC and Ax/LacZ/LacZ KIC were treated with vehicle $\left(K I C \mathrm{n}=9\right.$ and $\left.A x I^{\operatorname{Lac} Z / L a c Z} K I C \mathrm{n}=9\right)$ or gemcitabine $(25 \mathrm{mg} / \mathrm{kg}$, twice a week; KIC Gem, n=7; AxI Lacz/LacZ Gem, n=9) until animals were moribund. Therapy was initiated at 45 days of age. WT KIC mice that received vehicle had a median survival of 56 days, while treatment with gemcitabine only modestly extended the median survival by $12.5 \%$ to 63 days $(p=0.1062$ vs. $K I C)$. Similar to Figure $2 A, A x I^{\text {LacZ/LacZ } K I C}$ treated with vehicle had a relatively longer median survival (68 days) compared to vehicle treated $W T K I C$ ( $p=0.0098$ vs. $K I C)$.

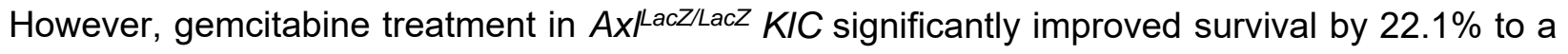
median of 83 days ( $p=0.0003$ vs. Axl LacZ/LacZ KIC; Fig. 2C). Consistent with the survival result, $\mathrm{YH} 2 \mathrm{AX}$ staining in tumor tissues demonstrated that gemcitabine-induced DNA double-strand break were potently promoted in AxILacz/LacZ KIC animals (Fig. 2D).

AXL deficiency results in a more active immune microenvironment

To investigate how AXL contributes to the immune landscape of PDA, RNA was isolated from KIC $(\mathrm{n}=2)$ and $A x{ }^{\text {LacZ/LacZ } K I C ~}(\mathrm{n}=3)$ tumors and was analyzed using Mouse PanCancer Immune Profiling Panel (NanoString Technologies). Upregulated (Red) and downregulated (Blue) gene programs/functions are shown in Figure 3A. Most immune cell functions as defined by NanoString were upregulated in $A x l^{\text {LacZ/LacZ }} K I C$, indicating a more active immune microenvironment.

To validate the Nanostring results, flow cytometry was performed on tumors from $K I C(n=11)$ and AxlLacZ/LacZ KIC $(\mathrm{n}=9)$. The number of total myeloid cell $\left(C D 11 b^{+}\right.$cells $)$was not changed in 
AxILacZ/LacZ KIC (Supplementary Fig. 4). However, the number of tumor-associated macrophages was significantly reduced (Fig. 3B). In addition to decreased recruitment, iNOS/Arginase-1 ratio in these macrophages was up-regulated in $A x^{\operatorname{LacZ} / L a c Z} K I C$ (Fig. 3B), indicating a transformation from immunosuppressive macrophages to inflammatory macrophages. Consistent with this we identified dramatic decrease of Arginase-1 expression by immunohistochemistry in Ax/Lacz/Lacz KIC tumor tissue (Fig. 3C).

Flow cytometry also revealed an increased number of $\mathrm{CD}^{+} \mathrm{T}$ cells and $\mathrm{CD} 335^{+} \mathrm{NK}$ cells in Axl Lacz/LacZ KIC while the CD4/CD3 and CD8/CD3 ratio were not changed (Fig. 3B and Supplementary Fig. 4). Elevated T cell infiltration (CD3) in AxILacZ/LacZ KIC was also observed by immunohistochemistry (Fig. 3C). These results suggest $A X L$ is important for the immunosuppressive microenvironment of PDA and highlights that immune suppression might contribute directly to chemoresistance and metastasis $(36,37)$.

AXL expression on tumor cells is critical for PDA progression and metastasis

We have demonstrated the effect of $A X L$ depletion on different cell populations in PDA. To investigate which AXL-positive cell population contributes to PDA progression, AXL was ablated using CRISPR-Cas9 in PDA cells isolated from a KPfC tumor. In vitro functional assays demonstrated that loss of $A X L(K O)$ does not influence cancer cell proliferation, but decreases cell migration and colony formation (Supplementary Fig. 5). Western blot analysis showed loss of AXL lead to decreased EMT transcription factor SLUG and mesenchymal marker Vimentin (Fig. 4A). Functional analysis showed that WT KPfC cells cultured in $30 \%$ matrigel $+70 \%$ collagen (38) formed projections indicating invasiveness while AXL KO KPfC cells lost the ability to invade (Fig. 4B). 
To determine whether AXL expression on tumor cells or host cells is more critical to PDA progression, WT and AXL KO KPfC cells were orthotopically injected into WT and AxlLacz/Lacz C57BL/6 mice. Injection of AXL KO KPfC cells into WT mice (KO WT, blue, n=8, 36 days) resulted in longer median survival compared to WT mice injected with WT KPfC cells (WT WT, black, n=8, 21 days, $p<0.0001$, Fig. 4C). However, AXL-deficient mice injected with WT KPfC cells (WT LacZ, red, $n=8,21$ days) showed the same median survival and metastases as WT mice injected with WT KPfC cells ( $p=0.9517$, Fig. 4D). Similarly, AXL-deficient mice injected with AXL KO KPfC cell (KO LacZ, green, $n=7,37$ days) resulted in longer median survival compared to AXL-deficient mice injected with WT KPfC cells ( $p=0.0001$, Fig. 4C). AXL-deficient mice injected with AXL KO KPfC cell showed similar median survival and metastases as WT mice injected with AXL KO KPfC cells $(p=0.25$, Fig. 4C). Gross liver metastases and metastatic incidence indicate that tumor cell expression of AXL was more important for metastasis than AXL expression by the host (Fig. 4D). Human PDA cell Panc1 and murine PDA cell Pan02 were also used to repeat the orthotopic experiment and the results were consistent (Supplementary Fig. 6A and 6C). To investigate metastasis using Pan02 cells, splenic injection was performed in WT and Ax/Lacz/Lacz C57BL/6 mice and similar results were obtained (Supplementary Fig. 6B). These in vivo results indicate that AXL expression on tumor cells is critical for PDA progression and metastasis. 


\section{Discussion}

Multiple strategies targeting AXL for cancer therapy have been developed and are being investigated in the clinic $(10,39)$; however, AXL expression within PDA microenvironment and the contribution of different AXL-positive cell populations to PDA progression have not been investigated extensively. Our lab used scRNA-seq to identify AXL-positive cells and characterize the effect of global loss of AXL in PDA GEMMs. Our study demonstrates that AXL is expressed by tumor cells, fibroblasts and macrophages and AXL expression on tumor cells contributes significantly to PDA progression and sensitivity to chemotherapy. Our data also document that AXL supports the immune suppressive microenvironment of PDA.

The phenotype of $A X L$-deficient PDA GEMMs is consistent with results from Goyette et al. (40) who crossed MMTV-Neu mice with AXL-deficient mice and found a decrease in the frequency and the total number of lung metastatic lesions in the absence of AXL (40). The characterization of $A X L$-deficient KIC mice provides a potent rationale for use AXL as a therapeutic target, especially in combination with standard chemotherapy or potentially immune checkpoint blockade. In fact, pharmacological inhibition of $A X L$ has similar effect in vivo. For example, bemcentinib (BGB324), a selective AXL inhibitor, sensitizes PDA mouse models to gemcitabine treatment and promotes an immune stimulatory landscape within the tumor (30). The efficacy of bemcentinib in combination with chemotherapy is being tested currently in pancreatic cancer patients (NCT03649321). Pharmacological inhibition of AXL has also been shown to decrease metastasis in breast cancer models $(19,41)$ and improve the efficacy of doxorubicin, BCR-ABL inhibitor, docetaxel, paclitaxel, EGFR inhibitor and nivolumab in breast cancer, chronic myelogenous leukemia, prostate cancer, uterine serous cancer, NSCLC and glioblastoma models, respectively $(11,19,42-45)$. 
The increased sensitivity of $A X L$-deficient $K I C$ mice to gemcitabine is likely to due to a more differentiated phenotype tumor cell phenotype that includes the up-regulation of nucleoside transporters such as ENT1. Consistent with this, an EMT gene signature and AXL expression by cancer cells was associated with chemoresistance screens in multiple cancer types $(4,8)$. These observations fit with our scRNA-seq of PDA GEMMs that revealed Axl expression is elevated in advanced tumors and is associated with tumor cells that have a mesenchymal-like phenotype. Furthermore, $A x I$ correlated negatively with classic epithelial markers. In fact, it was the most negatively associated marker among all the mesenchymal markers assessed. This highlights the use of $A X L$ as a mesenchymal cancer cell marker. Our data also suggest that $A X L$-positive mesenchymal PDA cells are a major contributor to PDA progression and metastasis, further emphasizing the rationale to target this subpopulation of tumor cells. Recently, an anti-AXL chimeric antigen receptor $\mathrm{T}$ cell therapy has shown promising efficacy in vitro with myelogenous leukemia cells and triple negative breast cancer cells $(46,47)$. AXL has also been investigated as a target for antibody drug conjugates in melanoma, lung, pancreatic and cervical cancer models, some of which have advanced to phase 1 clinical testing (48). However, the mechanism of how $A X L$ is up-regulated during cancer progression and how $A X L$ maintains epithelial plasticity in this subpopulation of cancer cells remains to be elucidated. To this end, we have recently shown that AXL stimulates the activity of tank-binding kinase 1 (TBK1) to drive epithelial plasticity in PDA (49). Current studies are focused on understanding if this pathway is dependent on mutant KRAS signaling and how TBK1 stimulates EMT.

The immunosuppressive microenvironment in $K I C$ tumor also contributes to chemoresistance and metastasis. We showed $A X L$-deficient $K I C$ tumors have a more inflammatory microenvironment 
with an increase in $\mathrm{T}$ cell and NK cell recruitment and a potent decrease in tumor associated macrophages, which were also polarized from immunosuppressive (Arginase- $1^{+}$) to anti-tumor $\left(\right.$ iNOS $\left.^{+}\right)$phenotype. This is consistent with the function of $A X L$ in efferocytosis, where it has been shown as a stimulator of apoptotic cell phagocytosis by macrophages (50). The polarization and recruitment of immune cells can also be influenced by crosstalk between AXL-positive cancer cells and immune cells. The Shieh group (51) showed that conditioned media from AXL-positive oral squamous cell carcinoma cells polarized tumor-associated macrophages to an M2-like phenotype (51). Aguilera et al (52) also demonstrated that AXL on breast cancer cells suppresses MHC-I expression and promotes cytokine secretion that supports and recruits myeloid cells (52) further enhancing immune suppression. Tumor associated macrophages are critical regulators of cytotoxic lymphocytes (53). These immunosuppressive macrophages can also be induced by conditioned media from PDA cells and result in the secretion of deoxycytidine that competitively inhibits gemcitabine uptake and metabolism (54).

Using orthotopic implant models we show that AXL-positive PDA cells are critical to PDA progression and metastasis while AXL-positive stroma appears to be nonessential in PDA progression and metastasis. However, blockade of $A X L$ on immune cells can lead to a reduction of metastasis in other types of cancers. Paolino et al. (25) reported that AXL, and its family members TYRO3 and MERTK, are ubiquitination substrates for E3 ubiquitin ligase casitas Blineage lymphoma proto-oncogene-b in NK cells and inhibition of TAM receptors enhances the anti-metastatic activity of NK cells in breast cancer models (25). Indeed, pharmacological inhibition of AXL by BGB324 or RXDX-106 improves the efficacy of immune checkpoint blockade in glioblastoma and colon cancer $(42,55)$. Spatially specified excision of $A X L$ will be required to 
bioRxiv preprint doi: https://doi.org/10.1101/2020.07.06.190363; this version posted July 7, 2020. The copyright holder for this preprint (which was not certified by peer review) is the author/funder, who has granted bioRxiv a license to display the preprint in perpetuity. It is made available under aCC-BY-NC-ND 4.0 International license.

determine the function of $A X L$ on different populations of stroma cells in the tumor microenvironment.

In summary, we demonstrate that global loss of AXL results in improved outcome in a PDA GEMM and a more immune active microenvironment. Our studies also highlight that tumor cell expression of $\mathrm{AXL}$ is an important contributor to PDA progression and chemoresistance. Our results in aggregate further validate $A X L$ as a therapeutic target in PDA. 


\section{Materials and Methods}

\section{Cell lines}

Human pancreatic cancer cell line Panc-1 was obtained from ATCC, and murine pancreatic cancer cell line, Pan02, was obtained from the Developmental Therapeutics Program at the National Cancer Institute at Frederick, Maryland. KPfC cell lines were derived from KPfC (Kras ${ }^{L S L-}$ G12D; Trp53 ${ }^{f / f f l} ; P D X^{C r e /+}$ ) mice. All cell lines were cultured in DMEM (Invitrogen) containing 5\% FBS and maintained in a humidified atmosphere with $5 \% \mathrm{CO}_{2}$ at $37^{\circ} \mathrm{C}$. Human cell lines were DNA fingerprinted for provenance using the Power-Plex 1.2 kit (Promega) and confirmed to be the same as the DNA fingerprint library maintained by ATCC. All cell lines were confirmed to be free of mycoplasma (e-Myco kit, Boca Scientific) before use.

\section{Animal studies}

Kras ${ }^{L S L-G 12 D ;}$ Cdkn2a ${ }^{f l / f l}$; Ptf1a ${ }^{\text {Cre/+ }}(K I C)$ mice were generated as previously described (49). AxILacz/LacZ mice were obtained from The Jackson Laboratory (AxItm1Dgen , stock 005777) and were crossed into KIC resulting in Ax/LacZ/LacZ KIC on a C57BI/6 background. At 45 days of age, male and female mice were randomized to receive vehicle (control, saline), or gemcitabine (25 mg/kg i.p. twice/week). Mice were weighed twice weekly and sacrificed when they were moribund or had $>20 \%$ weight loss. Tissues were fixed in $10 \%$ formalin or snap-frozen in liquid nitrogen for further studies.

Male and female 6-week-old C57BL/6 mice were obtained from an on-campus supplier. Male and female 6-week-old NON SCID mice were obtained from Charles River. Ax/Lacz/LacZ mice at the same age were generated in house. WT and AXL KO KPfC cells $\left(2.5 \times 10^{5}\right)$, Pan02 cells $\left(5 \times 10^{5}\right)$ and Panc1 cells $\left(1 \times 10^{6}\right)$ were injected orthotopically (and splenically for Pan02). KPfC and 
Pan02 bearing mice were weighed twice weekly and sacrificed when they were moribund or had $>20 \%$ weight loss. For splenically injection of Pan02, mice were sacrificed 7 weeks after injection. For Panc1 cells, mice were sacrificed 11 weeks after injection. Tissues were fixed in $10 \%$ formalin or snap-frozen in liquid nitrogen for further studies.

\section{Recombined Cdkn2a allele detection}

Liver micrometastasis was assessed by quantitative reverse transcription PCR (RT-PCR) for the recombined Cdkn2a(Ink4a/Arf) allele. Briefly, frozen livers were homogenized in SDS lysis buffer (100 mM Tris, pH 8.8; $5 \mathrm{mM}$ EDTA, 0.2\% SDS, $100 \mathrm{mM} \mathrm{NaCl}$ ) and digested at $56^{\circ} \mathrm{C}$ overnight. DNA was extracted using phenol/chloroform/isoamyl alcohol (25:24:1), and quantitative RT-PCR was performed using iTaq SYBR Green Supermix (Bio-Rad). The following validated primers were used for analysis of Cdkn2a: GCCGACATCTCTCTGACCTC (forward) and CTCGAACCAGGTTTCCATTG (reverse). Each sample was analyzed in triplicate.

\section{CRISPR-Cas9 knockout of AXL}

Guide RNAs targeting $A x I$ were cloned into the $\mathrm{pX} 330$ plasmid. The reconstructed plasmid was transfected into cells using lipofectamine 2000. 8 hours after transfection, medium was changed to normal medium. 48 hours after transfection, GFP ${ }^{+}$cells were sorted out and plated in 96 -well plates at 1 cell/well. AXL knockout cells were confirmed by Western blot. Sequences for guide RNAs are as follows: Human AXL GuideA for: caccgctgcctagccgaagctgat; rev: aaacatcagcttcggctaggcagc; Human AXL GuideB for: caccgcacccttatcacatccgcg; rev: aaaccgcggatgtgataaggggtgc. Mouse Axl GuideA for: caccggagcttttccagccgaagc; rev: 
aaacgcttcggctggaaaagctcc; Mouse Axl GuideB for: caccgctcacaccccgtatcacatc; rev: aaacgatgtgatacggggtgtgagc.

\section{Nanostring analysis}

KIC and $A x I^{L a c z / L a c Z}$ KIC tumor tissues were lysed in RLT lysis buffer and purified according to the manufacturer's instructions (QIAGEN). RNA was sent to the Genomic and Microarray Core Facility at UTSW and analyzed using a preassembled nCounter PanCancer Immune Profiling Panel (mouse) and the nCounter system (NanoString Technologies) according to the manufacturer's instructions. Samples were normalized based on the geometric means of the supplied positive controls and the panel of housekeeping genes, as recommended by the manufacturer. Only genes that were significantly different $(P<0.05$; t test, false discover rate adjusted) and at least 1.5-fold differentially expressed between groups were considered.

\section{Bioinformatic analyses of single cell RNA sequencing data}

Data were generated from our previous publication and analyzed as previously described (34). Spearman correlations of gene-gene expression in cancer cells were calculated using the correlation function from the stat package in $\mathrm{R}$.

\section{Histology and tissue analysis}

Formalin-fixed tissues were embedded in paraffin and cut in 5-mm sections. Sections were evaluated by H\&E, Alcian blue and immunohistochemical analysis using antibodies specific for CD31 (Cell Signaling, 77699), KI67 (Abcam, ab15580), cleaved caspase-3 (CC3, Cell Signaling, 
9661), aSMA (Biocare Medical CM 001), CDH11 (LifeSpan BioSciences, LS-B2308), E-cadherin (Cell Signaling, 3195), Vimentin (Cell Signaling, 5741), equilibrative nucleoside transporter 1 (ENT1, Abcam, ab135756), yH2AX (Novus, NB100-384), CD3 (Invitrogen, MA5-17043), Arginase 1 (Arg1, Cell Signaling, 93668), SOX9 (EMD Millipore, AB5535), PDGFRa (LifeSpan BioSciences, LS-B8655), and $\beta$-Galactosidase (Abcam, ab9361). Negative controls included omission of primary antibody. Color images were obtained with a Nikon Eclipse E600 microscope using a Niko Digital Dx1200me camera and ACT1 software, or Hamamatsu NanoZoomer 2.0-HT at Whole Brain Microscopy Facility of UTSW. Pictures were analyzed using ImageJ.

\section{MTS assay}

The MTS colorimetric assay (Promega) was performed as per the manufacturer's instructions. Cells were plated at 1,000 cells/well in tissue culture-treated 96-well plates. On each day, 20 $\mu \mathrm{l} /$ well MTS was added, followed by a 2-hour incubation at $37^{\circ} \mathrm{C}$, and then the absorbance was read at $490 \mathrm{~nm}$ on a plate reader.

\section{Wound healing assay}

Cells were cultured in 24-well tissue culture plates at high density ( $\sim 90 \%$ confluence $)$ in $0.5 \mathrm{ml}$ of media with 5\% FBS. Uniform scratches were made down the center of each well with a p200 pipette tip, cells were gently washed with PBS to remove the loose cell debris, and were cultured in media with $1 \%$ FBS. Images from the center of each well were taken at the indicated time points. The wound width was measured using ImageJ and percentage of wound healing (migration) was calculated based on the initial wound width. 


\section{Liquid colony-forming assay}

Cell lines were cultured in 6-well tissue culture plates at low density ( 200 cells/well) in $2 \mathrm{ml}$ of media with $5 \%$ FBS and allowed to settle for 2 weeks or until marked colony formation. Cells were then fixed with $10 \%$ formalin and stained with crystal violet. Images were analyzed with ImageJ.

\section{Organotypic culture}

For each cell line, 2000 cells were plated in 8-well chamber slides onto a base layer of growth factor-reduced Matrigel (5 mg/ml, BD Biosciences, Lot A6532) and collagen type I (1.5-2.1 mg/ml, BD Biosciences) and cultured for 2 days in a humidified $37^{\circ} \mathrm{C}$ incubator as previously described (38).

\section{Western blot analysis}

KPfC cells were lysed using RIPA buffer (Cell Signaling, 9806), supernatants were recovered by centrifugation, protein concentration was measured using a Pierce BCA Protein Assay Kit (Thermo Fisher Scientific, 23225), and equal amounts of total protein were separated by SDSPAGE. Proteins were transferred to nitrocellulose membranes (Bio-Rad), followed by a blocking in $5 \%$ BSA in TBST $\left(0.05 \%\right.$ Tween-20). The membranes were incubated overnight at $4^{\circ} \mathrm{C}$ with primary antibody, Actin (Sigma, A2066), AXL (Santa Cruz, sc-1096), SLUG (Cell Signaling, 9585), and Vimentin (Cell Signaling, 5741) followed by corresponding horseradish peroxidaseconjugated secondary antibody (Jackson ImmunoResearch). Specific bands were detected by using WesternSure PREMIUM chemiluminescent substrate (Li-Cor) on a Li-Cor imaging system (Odyssey-Fc). 


\section{Flow cytometry}

Tumors were digested with a cocktail containing collagenase I (45 $\mu / \mathrm{ml}$; Worthington), collagenase II (15 $\mu / \mathrm{ml}$; Worthington), collagenase III (45 $\mu / \mathrm{ml}$; Worthington), collagenase IV (45 $\mu / \mathrm{ml}$; Worthington), elastase $(0.075 \mu / \mathrm{ml}$; Worthington), hyaluronidase (30 $\mu / \mathrm{ml}$; MilliporeSigma), and DNase type I $\left(25 \mu / \mathrm{ml}\right.$; MilliporeSigma) for 40 minutes at $37^{\circ} \mathrm{C}$ and passed through a $70-\mu \mathrm{m}$ cell strainer (Falcon). Suspensions were washed twice with PBS and stained with Fixable Viability Dye (Thermo Fisher) for 1 hour. The cell suspensions were then washed and stained with antibodies detecting CD11b (BD Bioscience, 557657), Ly-6C (BD Bioscience, 562728), Ly-6G (BD Bioscience, 740953), F4/80 (Biolegend, 123132), CD11c (BD Bioscience, 564079), I-A/I-E (BD Bioscience, 562009), CD3 (BD Bioscience, 553061), CD4 (BD Bioscience, 562891), CD8 (BD Bioscience, 563332), and CD335 (Biolegend, 137621), for 1 hour at $4^{\circ} \mathrm{C}$. Surface-stained cells were fixed, permeabilized, and stained for intracellular markers Arginase-1 (R\&D Systems, IC5868P) and iNOS (Thermo Fisher, 17-5920-82). Cells were analyzed using FACS LSRFortessa SORP, and analysis was performed using FlowJo, with the help of the Moody Foundation flow cytometry facility at University of Texas Southwestern Medical Center.

\section{Statistical analysis}

Data are reported as means \pm SD. Statistical analyses of mouse model survival data were performed using analysis of variance (ANOVA) with Mantel-Cox test of significance difference using GraphPad Prism (version 8.0.1). Statistical analysis of immunohistorchemistry was performed with a 2-tailed t test or ANOVA using GraphPad Prism. For all analyses, $\mathrm{P}<0.05$ was considered statistically significant. 


\section{Study approval}

All animals were housed in a pathogen-free facility with 24-hour access to food and water. Experiments were approved by, and conducted in accordance with, the Institutional Animal Care and Use Committee at the University of Texas Southwestern Medical Center, which are compliant with the guidelines proposed by the NIH Guide for the Care and Use of Laboratory Animal.

\section{Author contributions}

WD and RAB conceived and designed the study. WD, HH, ZW, JET, NB, YZ and NB acquired data and performed analysis and interpretation of data. WD wrote the manuscript. RAB reviewed and revised the manuscript. RAB supervised the study.

\section{Acknowledgements}

We thank Drs. Jill Westcott, Gray Pearson, Srinivas Malladi and members of the Brekken lab for helpful discussion and Dave Primm for editorial assistance. The work was supported by NIH grants R01 CA192381 and U54 CA210181 Project 2 and the Effie Marie Cain Scholarship in Angiogenesis Research to RAB. The funders had no role in study design, data collection and analysis, decision to publish, or preparation of the manuscript.

\section{Conflict of Interest}

RAB discloses he is a consultant for BerGenBio ASA and that he receives funding for projects distinct from the current study from BerGenBio ASA and Tolero, companies developing AxI inhibitors. JBL discloses he is an employee and stockholder of BerGenBio ASA. 


\section{References}

1. Siegel RL, Miller KD, and Jemal A. Cancer statistics, 2019. CA Cancer J Clin. 2019;69(1):7-34.

2. Liu $Q$, Liao $Q$, and Zhao $Y$. Chemotherapy and tumor microenvironment of pancreatic cancer. Cancer Cell Int. 2017;17(68.

3. Arumugam T, Ramachandran V, Fournier KF, Wang H, Marquis L, Abbruzzese JL, Gallick GE, Logsdon CD, McConkey DJ, and Choi W. Epithelial to mesenchymal transition contributes to drug resistance in pancreatic cancer. Cancer Res. 2009;69(14):5820-8.

4. Byers LA, Diao L, Wang J, Saintigny P, Girard L, Peyton M, Shen L, Fan Y, Giri U, Tumula PK, et al. An epithelial-mesenchymal transition gene signature predicts resistance to EGFR and PI3K inhibitors and identifies Axl as a therapeutic target for overcoming EGFR inhibitor resistance. Clin Cancer Res. 2013;19(1):279-90.

5. Zheng X, Carstens JL, Kim J, Scheible M, Kaye J, Sugimoto H, Wu CC, LeBleu VS, and Kalluri R. Epithelial-to-mesenchymal transition is dispensable for metastasis but induces chemoresistance in pancreatic cancer. Nature. 2015;527(7579):525-30.

6. Fischer KR, Durrans A, Lee S, Sheng J, Li F, Wong ST, Choi H, El Rayes T, Ryu S, Troeger J, et al. Epithelial-to-mesenchymal transition is not required for lung metastasis but contributes to chemoresistance. Nature. 2015;527(7579):472-6.

7. Farmer P, Bonnefoi H, Anderle P, Cameron D, Wirapati P, Becette V, Andre S, Piccart M, Campone $M$, Brain $E$, et al. A stroma-related gene signature predicts resistance to neoadjuvant chemotherapy in breast cancer. Nat Med. 2009;15(1):68-74.

8. Hangauer MJ, Viswanathan VS, Ryan MJ, Bole D, Eaton JK, Matov A, Galeas J, Dhruv HD, Berens $\mathrm{ME}$, Schreiber SL, et al. Drug-tolerant persister cancer cells are vulnerable to GPX4 inhibition. Nature. 2017;551(7679):247-50.

9. Lemke G. Biology of the TAM receptors. Cold Spring Harb Perspect Biol. 2013;5(11):a009076.

10. Du W, and Brekken RA. Does Axl have potential as a therapeutic target in pancreatic cancer? Expert Opin Ther Targets. 2018.

11. Zhang Z, Lee JC, Lin L, Olivas V, Au V, LaFramboise T, Abdel-Rahman M, Wang X, Levine AD, Rho $\mathrm{JK}$, et al. Activation of the AXL kinase causes resistance to EGFR-targeted therapy in lung cancer. Nat Genet. 2012;44(8):852-60.

12. Li Y, Jia L, Liu C, Gong Y, Ren D, Wang N, Zhang X, and Zhao Y. Axl as a downstream effector of TGF-beta1 via PI3K/Akt-PAK1 signaling pathway promotes tumor invasion and chemoresistance in breast carcinoma. Tumour Biol. 2015;36(2):1115-27.

13. Asiedu MK, Beauchamp-Perez FD, Ingle JN, Behrens MD, Radisky DC, and Knutson KL. AXL induces epithelial-to-mesenchymal transition and regulates the function of breast cancer stem cells. Oncogene. 2014;33(10):1316-24.

14. Wilson C, Ye X, Pham T, Lin E, Chan S, McNamara E, Neve RM, Belmont L, Koeppen H, Yauch RL, et al. AXL inhibition sensitizes mesenchymal cancer cells to antimitotic drugs. Cancer Res. 2014;74(20):5878-90.

15. Balaji K, Vijayaraghavan S, Diao L, Tong P, Fan Y, Carey JP, Bui TN, Warner S, Heymach JV, Hunt KK, et al. AXL Inhibition Suppresses the DNA Damage Response and Sensitizes Cells to PARP Inhibition in Multiple Cancers. Mol Cancer Res. 2017;15(1):45-58.

16. Gjerdrum C, Tiron C, Hoiby T, Stefansson I, Haugen H, Sandal T, Collett K, Li S, McCormack E, Gjertsen BT, et al. Axl is an essential epithelial-to-mesenchymal transition-induced regulator of breast cancer metastasis and patient survival. Proc Natl Acad Sci U S A. 2010;107(3):1124-9.

17. Li Y, Jia L, Ren D, Liu C, Gong Y, Wang N, Zhang X, and Zhao Y. Axl mediates tumor invasion and chemosensitivity through $\mathrm{PI} 3 \mathrm{~K} / \mathrm{Akt}$ signaling pathway and is transcriptionally regulated by slug in breast carcinoma. IUBMB Life. 2014;66(7):507-18. 
18. Antony J, Tan TZ, Kelly Z, Low J, Choolani M, Recchi C, Gabra H, Thiery JP, and Huang RY. The GAS6AXL signaling network is a mesenchymal (Mes) molecular subtype-specific therapeutic target for ovarian cancer. Sci Signal. 2016;9(448):ra97.

19. Wang C, Jin H, Wang N, Fan S, Wang Y, Zhang Y, Wei L, Tao X, Gu D, Zhao F, et al. Gas6/Axl Axis Contributes to Chemoresistance and Metastasis in Breast Cancer through Akt/GSK-3beta/betacatenin Signaling. Theranostics. 2016;6(8):1205-19.

20. Kariolis MS, Miao YR, Diep A, Nash SE, Olcina MM, Jiang D, Jones DS, 2nd, Kapur S, Mathews, II, Koong AC, et al. Inhibition of the GAS6/AXL pathway augments the efficacy of chemotherapies. $J$ Clin Invest. 2017;127(1):183-98.

21. Lew ED, Oh J, Burrola PG, Lax I, Zagorska A, Traves PG, Schlessinger J, and Lemke G. Differential TAM receptor-ligand-phospholipid interactions delimit differential TAM bioactivities. Elife. 2014;31

22. Seitz HM, Camenisch TD, Lemke G, Earp HS, and Matsushima GK. Macrophages and dendritic cells use different $\mathrm{Axl} /$ Mertk/Tyro3 receptors in clearance of apoptotic cells. J Immunol. 2007;178(9):5635-42.

23. Schmid ET, Pang IK, Carrera Silva EA, Bosurgi L, Miner JJ, Diamond MS, Iwasaki A, and Rothlin CV. AXL receptor tyrosine kinase is required for T cell priming and antiviral immunity. Elife. 2016;5(

24. Park IK, Trotta R, Yu J, and Caligiuri MA. Axl/Gas6 pathway positively regulates FLT3 activation in human natural killer cell development. Eur J Immunol. 2013;43(10):2750-5.

25. Paolino M, Choidas A, Wallner S, Pranjic B, Uribesalgo I, Loeser S, Jamieson AM, Langdon WY, Ikeda F, Fededa JP, et al. The E3 ligase Cbl-b and TAM receptors regulate cancer metastasis via natural killer cells. Nature. 2014;507(7493):508-12.

26. Zhao GJ, Zheng JY, Bian JL, Chen LW, Dong N, Yu Y, Hong GL, Chandoo A, Yao YM, and Lu ZQ. Growth Arrest-Specific 6 Enhances the Suppressive Function of CD4(+)CD25(+) Regulatory T Cells Mainly through AxI Receptor. Mediators Inflamm. 2017;2017(6848430.

27. Rothlin CV, Ghosh S, Zuniga El, Oldstone MB, and Lemke G. TAM receptors are pleiotropic inhibitors of the innate immune response. Cell. 2007;131(6):1124-36.

28. Koorstra JB, Karikari CA, Feldmann G, Bisht S, Rojas PL, Offerhaus GJ, Alvarez H, and Maitra A. The $A x l$ receptor tyrosine kinase confers an adverse prognostic influence in pancreatic cancer and represents a new therapeutic target. Cancer Biol Ther. 2009;8(7):618-26.

29. Song X, Wang H, Logsdon CD, Rashid A, Fleming JB, Abbruzzese JL, Gomez HF, Evans DB, and Wang $\mathrm{H}$. Overexpression of receptor tyrosine kinase $A \mathrm{xl}$ promotes tumor cell invasion and survival in pancreatic ductal adenocarcinoma. Cancer. 2011;117(4):734-43.

30. Ludwig KF, Du W, Sorrelle NB, Wnuk-Lipinska K, Topalovski M, Toombs JE, Cruz VH, Yabuuchi S, Rajeshkumar NV, Maitra A, et al. Small-Molecule Inhibition of Axl Targets Tumor Immune Suppression and Enhances Chemotherapy in Pancreatic Cancer. Cancer Res. 2018;78(1):246-55.

31. Kirane A, Ludwig KF, Sorrelle N, Haaland G, Sandal T, Ranaweera R, Toombs JE, Wang M, Dineen SP, Micklem D, et al. Warfarin Blocks Gas6-Mediated Axl Activation Required for Pancreatic Cancer Epithelial Plasticity and Metastasis. Cancer Res. 2015;75(18):3699-705.

32. Beg MS, Gupta A, Sher D, Ali S, Khan S, Gao A, Stewart T, Ahn C, Berry J, and Mortensen EM. Impact of Concurrent Medication Use on Pancreatic Cancer Survival-SEER-Medicare Analysis. Am J Clin Oncol. 2018;41(8):766-71.

33. Haaland GS, Falk RS, Straume O, and Lorens JB. Association of Warfarin Use With Lower Overall Cancer Incidence Among Patients Older Than 50 Years. JAMA Intern Med. 2017.

34. Hosein AN, Huang H, Wang Z, Parmar K, Du W, Huang J, Maitra A, Olson E, Verma U, and Brekken RA. Cellular heterogeneity during mouse pancreatic ductal adenocarcinoma progression at singlecell resolution. JCI Insight. 2019;5( 
35. Aguirre AJ, Bardeesy N, Sinha M, Lopez L, Tuveson DA, Horner J, Redston MS, and DePinho RA. Activated Kras and Ink4a/Arf deficiency cooperate to produce metastatic pancreatic ductal adenocarcinoma. Genes Dev. 2003;17(24):3112-26.

36. Kudo-Saito C, Shirako H, Takeuchi T, and Kawakami Y. Cancer metastasis is accelerated through immunosuppression during Snail-induced EMT of cancer cells. Cancer Cell. 2009;15(3):195-206.

37. Mitchem JB, Brennan DJ, Knolhoff BL, Belt BA, Zhu Y, Sanford DE, Belaygorod L, Carpenter D, Collins L, Piwnica-Worms D, et al. Targeting tumor-infiltrating macrophages decreases tumorinitiating cells, relieves immunosuppression, and improves chemotherapeutic responses. Cancer Res. 2013;73(3):1128-41.

38. Westcott JM, Prechtl AM, Maine EA, Dang TT, Esparza MA, Sun H, Zhou Y, Xie Y, and Pearson GW. An epigenetically distinct breast cancer cell subpopulation promotes collective invasion. $J$ Clin Invest. 2015;125(5):1927-43.

39. Du W, Huang H, Sorrelle N, and Brekken RA. Sitravatinib potentiates immune checkpoint blockade in refractory cancer models. JCl Insight. 2018;3(21).

40. Goyette MA, Duhamel S, Aubert L, Pelletier A, Savage P, Thibault MP, Johnson RM, Carmeliet P, Basik M, Gaboury L, et al. The Receptor Tyrosine Kinase AXL Is Required at Multiple Steps of the Metastatic Cascade during HER2-Positive Breast Cancer Progression. Cell Rep. 2018;23(5):147690.

41. Leconet W, Chentouf $M$, du Manoir S, Chevalier C, Sirvent A, Ait-Arsa I, Busson M, Jarlier M, Radosevic-Robin N, Theillet C, et al. Therapeutic Activity of Anti-AXL Antibody against TripleNegative Breast Cancer Patient-Derived Xenografts and Metastasis. Clin Cancer Res. 2017;23(11):2806-16.

42. Sadahiro H, Kang KD, Gibson JT, Minata M, Yu H, Shi J, Chhipa R, Chen Z, Lu S, Simoni Y, et al. Activation of the Receptor Tyrosine Kinase AXL Regulates the Immune Microenvironment in Glioblastoma. Cancer Res. 2018;78(11):3002-13.

43. Ben-Batalla I, Erdmann R, Jorgensen $H$, Mitchell R, Ernst $T$, von Amsberg $G$, Schafhausen $P$, Velthaus JL, Rankin S, Clark RE, et al. Axl Blockade by BGB324 Inhibits BCR-ABL Tyrosine Kinase Inhibitor-Sensitive and -Resistant Chronic Myeloid Leukemia. Clin Cancer Res. 2017;23(9):2289300.

44. Palisoul ML, Quinn JM, Schepers E, Hagemann IS, Guo L, Reger K, Hagemann AR, McCourt CK, Thaker PH, Powell MA, et al. Inhibition of the Receptor Tyrosine Kinase AXL Restores Paclitaxel Chemosensitivity in Uterine Serous Cancer. Mol Cancer Ther. 2017;16(12):2881-91.

45. Lin JZ, Wang ZJ, De W, Zheng M, Xu WZ, Wu HF, Armstrong A, and Zhu JG. Targeting AXL overcomes resistance to docetaxel therapy in advanced prostate cancer. Oncotarget. 2017;8(25):41064-77.

46. Cho JH, Okuma A, Al-Rubaye D, Intisar E, Junghans RP, and Wong WW. Engineering Axl specific CAR and SynNotch receptor for cancer therapy. Sci Rep. 2018;8(1):3846.

47. Wei J, Sun H, Zhang A, Wu X, Li Y, Liu J, Duan Y, Xiao F, Wang H, Lv M, et al. A novel AXL chimeric antigen receptor endows $T$ cells with anti-tumor effects against triple negative breast cancers. Cell Immunol. 2018.

48. Boshuizen J, Koopman LA, Krijgsman O, Shahrabi A, van den Heuvel EG, Ligtenberg MA, Vredevoogd DW, Kemper K, Kuilman T, Song JY, et al. Cooperative targeting of melanoma heterogeneity with an AXL antibody-drug conjugate and BRAF/MEK inhibitors. Nat Med. 2018;24(2):203-12.

49. Cruz VH, Arner EN, Du W, Bremauntz AE, and Brekken RA. Axl-mediated activation of TBK1 drives epithelial plasticity in pancreatic cancer. JCI Insight. 2019;5(

50. Lemke G. How macrophages deal with death. Nat Rev Immunol. 2019;19(9):539-49. 
51. Chiu KC, Lee CH, Liu SY, Chou YT, Huang RY, Huang SM, and Shieh YS. Polarization of tumorassociated macrophages and Gas6/Axl signaling in oral squamous cell carcinoma. Oral Oncol. 2015;51(7):683-9.

52. Aguilera TA, Rafat M, Castellini L, Shehade H, Kariolis MS, Hui AB, Stehr H, von Eyben R, Jiang D, Ellies LG, et al. Reprogramming the immunological microenvironment through radiation and targeting Axl. Nat Commun. 2016;7(13898.

53. Ellyard JI, Quah BJ, Simson L, and Parish CR. Alternatively activated macrophage possess antitumor cytotoxicity that is induced by IL-4 and mediated by arginase-1. I Immunother. 2010;33(5):443-52.

54. Halbrook CJ, Pontious C, Kovalenko I, Lapienyte L, Dreyer S, Lee HJ, Thurston G, Zhang Y, Lazarus J, Sajjakulnukit $P$, et al. Macrophage-Released Pyrimidines Inhibit Gemcitabine Therapy in Pancreatic Cancer. Cell Metab. 2019;29(6):1390-9 e6.

55. Yokoyama Y, Lew ED, Seelige R, Tindall EA, Walsh C, Fagan PC, Lee JY, Nevarez R, Oh J, Tucker KD, et al. Immuno-oncological Efficacy of RXDX-106, a Novel TAM (TYRO3, AXL, MER) Family SmallMolecule Kinase Inhibitor. Cancer Res. 2019;79(8):1996-2008. 
Figure \& Legends

Figure 1

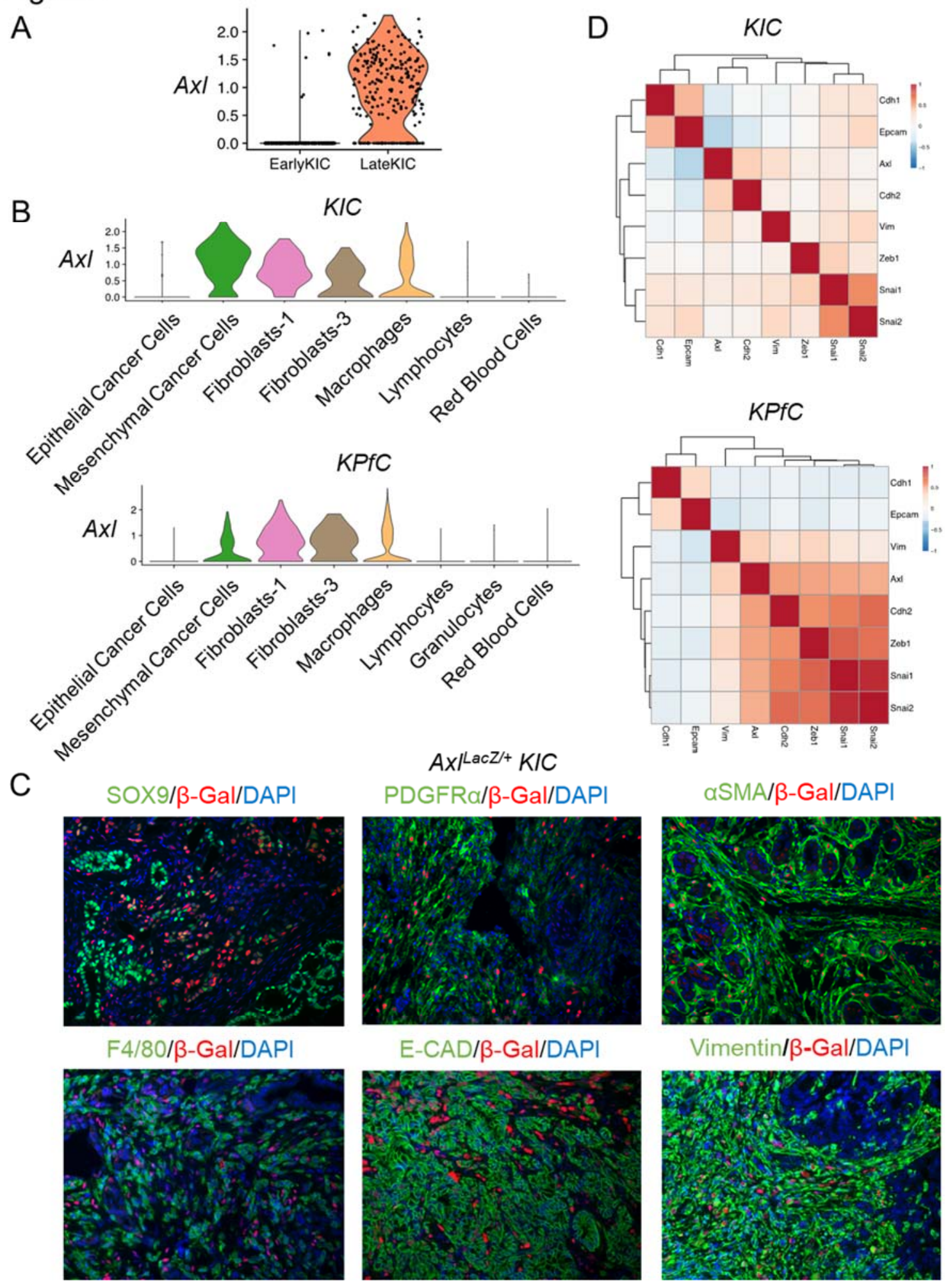


Figure 1. AXL is expressed in mesenchymal PDA tumor cells. A) Single cell RNA sequencing was performed with tumors harvested from early stage and late stage of $K I C$ mice. Axl expression is shown by violin plot. B) Single cell RNA sequencing was performed with tumors harvested from KIC (Kras ${ }^{L S L-G 12 D /+}$, Ink4a/Arflox/lox,$\left.P t f 1 a^{C r e /+}\right)$ or KPfC $\left(K^{2}\right.$ ras $\left.^{L S L-G 12 D}, P 53^{l o x / l o x}, P D X^{C r e /+}\right)$ mice. AxI expression in different populations is shown by violin plot for each mouse model. C) Tumor tissues from $A x I^{\mathrm{LacZ} /+}$ KIC mice were evaluated for co-localization of $\beta$-galactosidase and indicated targets. $\beta$-galactosidase staining is used to identify the expression of AXL. D) Correlation plots with $A x I$ and EMT genes in KIC and KPfC models were generated by analyzing the EMT gene expression within the cancer cell clusters from each model. A positive correlation is highlighted in red and negative correlation is highlighted in blue. 
Figure 2

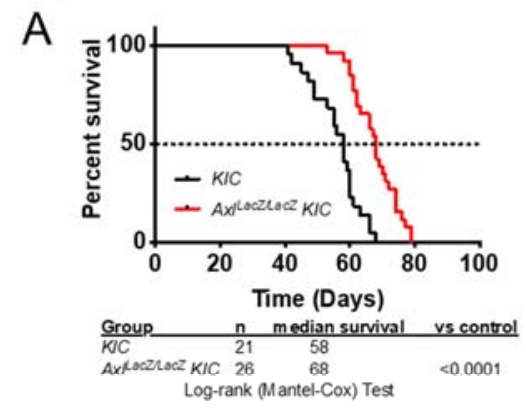

B

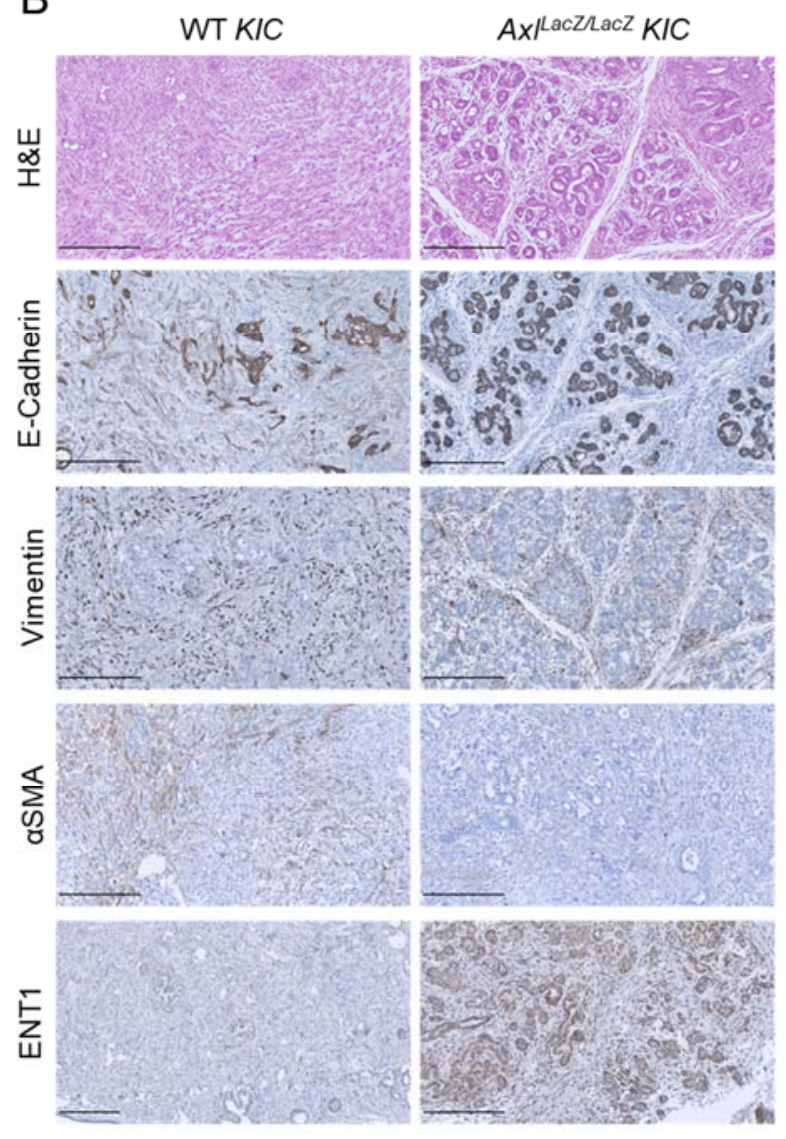

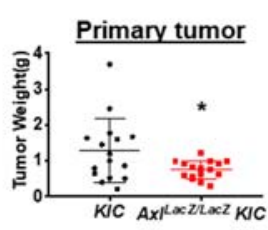
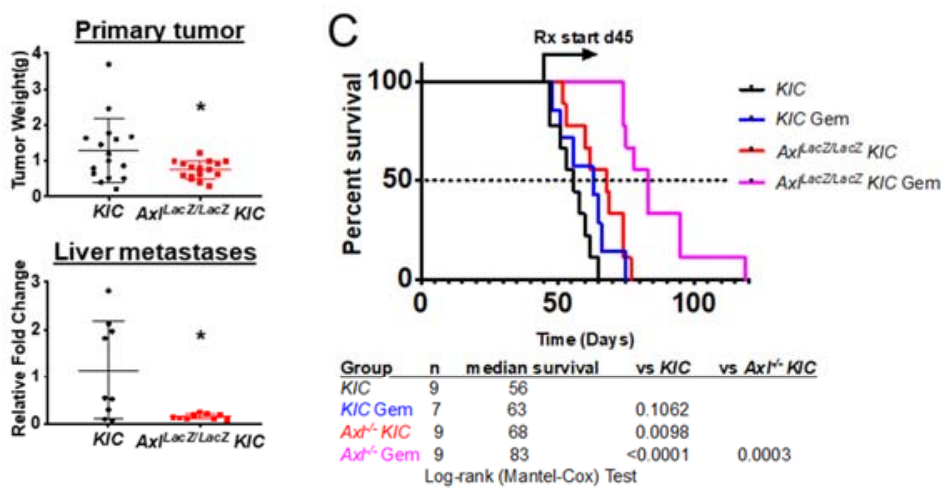

D $\quad \mathrm{yH} 2 \mathrm{AX}$
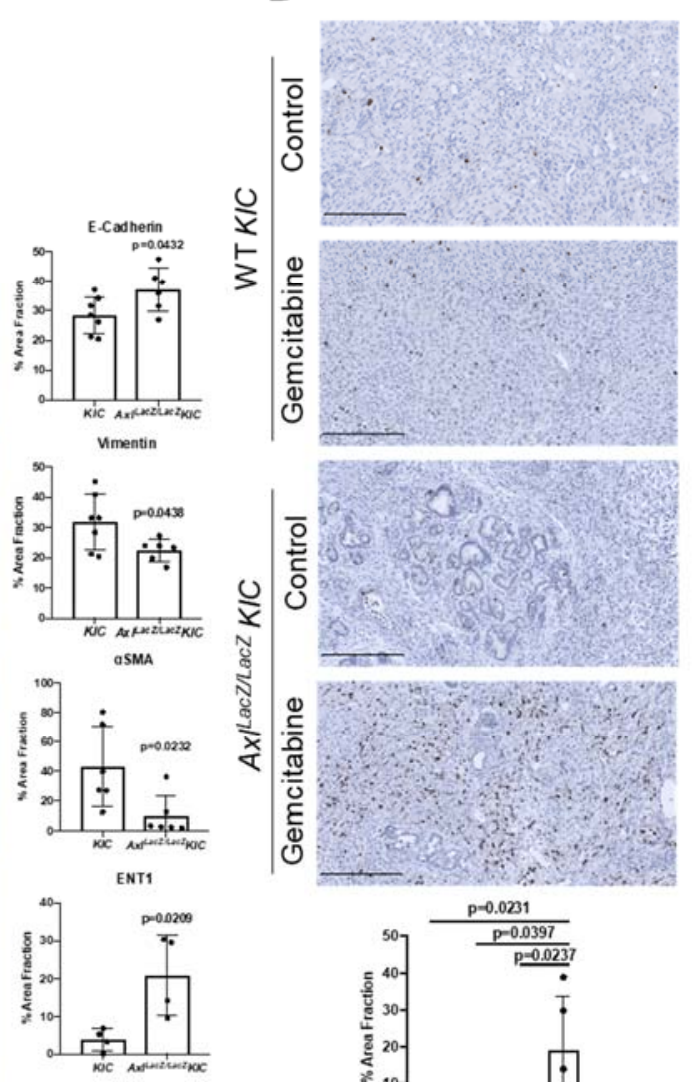

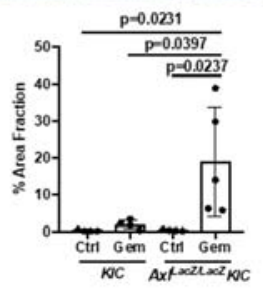

Figure 2. AXL deficiency prolongs survival, inhibits metastasis and EMT, and improves gemcitabine efficacy in a GEMM of PDA. A) $K I C(n=21)$ and Axllacz/Lacz $K I C(n=26)$ mice were enrolled in a survival study. Primary tumor weight and liver metastases were measured at the end of the survival study. Liver metastases were determined by detecting recombined Ink4a/Arf in 
liver tissues. Data are displayed as mean $\pm \mathrm{SD}$. ${ }^{*} \mathrm{P}<0.05$; by t-test. B) Tumor tissues from $K I C$

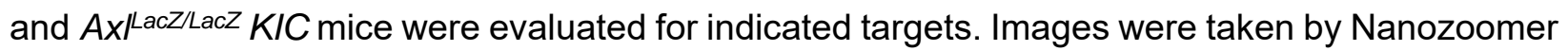
to cover the whole tissue and analyzed using ImageJ software. quantification of \% area fraction is shown. Each data point is the average of one sample. Data are displayed as mean \pm SD. P

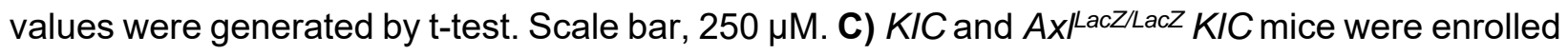
in a survival study and randomized to vehicle and gemcitabine (Gem, $25 \mathrm{mg} / \mathrm{kg}$ ip twice a week). Therapy was initiated on day 45 and maintained until sacrifice. D) Tumor tissues from (C) were evaluated for $\mathrm{yH} 2 \mathrm{AX}$. Images were taken by Nanozoomer to cover the whole tissue and analyzed using ImageJ software. Quantification of \% area fraction is shown. Each data point is the average of one sample. Data are displayed as mean \pm SD. P values were generated by ANOVA. Scale bar, $250 \mu \mathrm{M}$. 
bioRxiv preprint doi: https://doi.org/10.1101/2020.07.06.190363; this version posted July 7, 2020. The copyright holder for this preprint (which was not certified by peer review) is the author/funder, who has granted bioRxiv a license to display the preprint in perpetuity. It is made available under aCC-BY-NC-ND 4.0 International license.

Figure 3

A

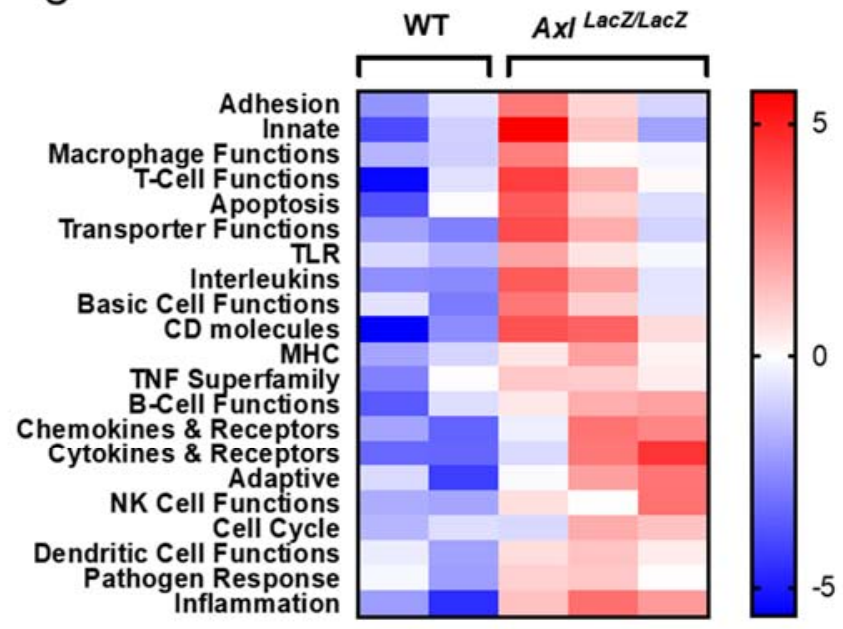

B
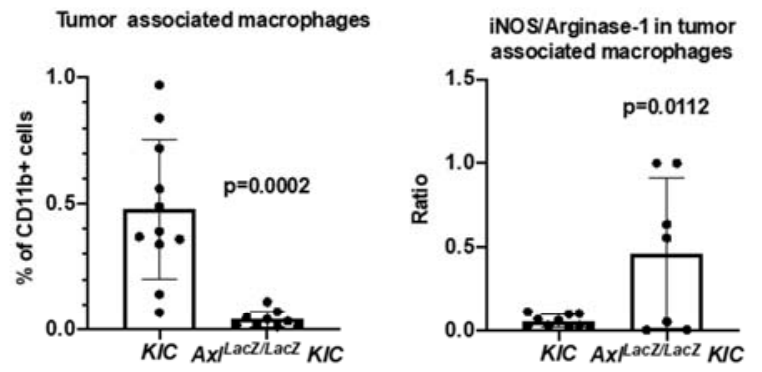

$\mathrm{CD} 3+\mathrm{T}$ cells
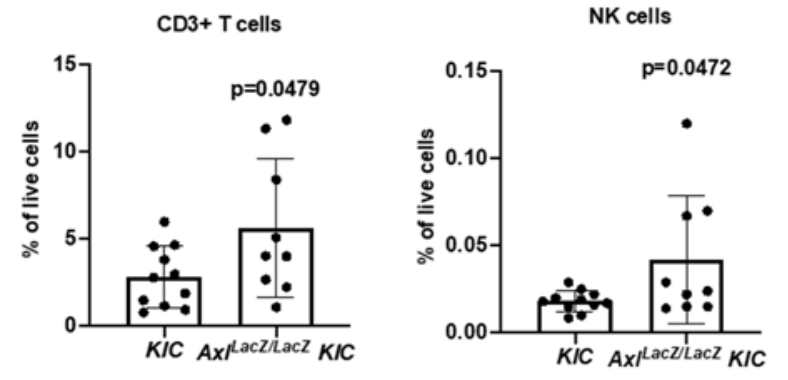

C
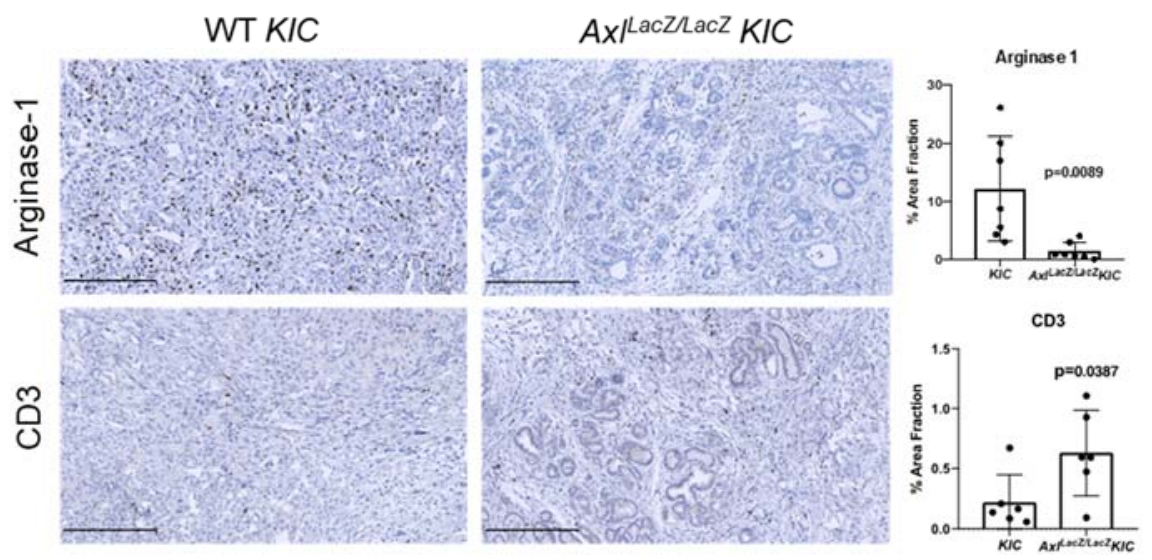
Figure 3. AXL deficiency results in a more active immune microenvironment. A) RNA was isolated from $K I C(n=2)$ and $A x I^{L a c z / L a c Z} K I C(n=3)$ tumors and analyzed using Mouse PanCancer Immune Profiling Panel (NanoString Technologies). Upregulated (Red) and downregulated (Blue) gene programs/functions are shown. B) Flow cytometry of tumor-associated myeloid and lymphoid cells from KIC $(n=11)$ and AxlLacz/LacZ KIC $(n=9)$. Tumor associated macrophages (CD11b+ Ly6G- Ly6C- F4/80+ $\left.\mathrm{CD}^{+} 1 \mathrm{c}^{+} \mathrm{MHCI}^{+}\right)$, iNOS ${ }^{+} /$Arginase $-^{+}$macrophage ratio, $\mathrm{CD}^{+} \mathrm{T}^{+}$ cells, and CD335+ NK cells were analyzed. P values were generated by $t$ test. C) Tumor tissues from $K I C$ and $A x I^{L a c Z / L a c Z} K I C$ mice were evaluated for indicated targets. Images were taken by Nanozoomer to cover the whole tissue and analyzed using ImageJ software. Quantification of \% area fraction is shown. Each data point is the average of one sample. Data are displayed as mean \pm SD. P values were generated by t-test. Scale bar, $250 \mu \mathrm{M}$. 


\section{Figure 4}

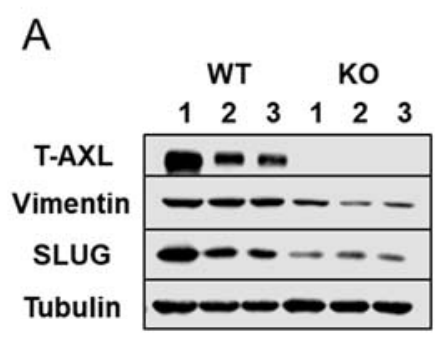

B

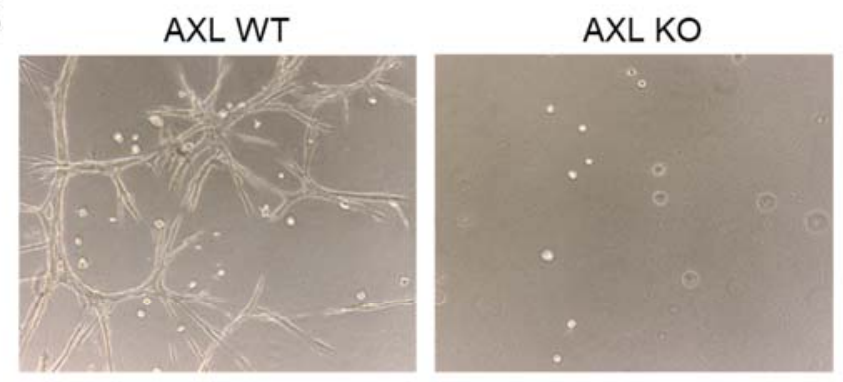

C

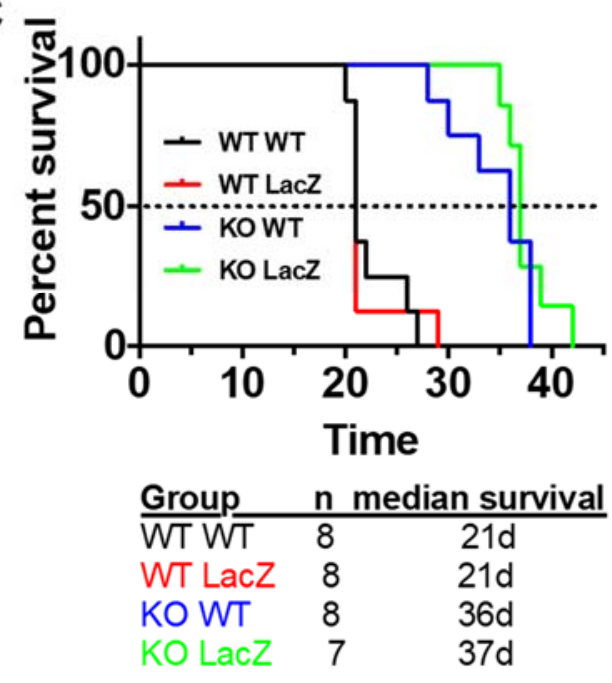

$\mathrm{D}$

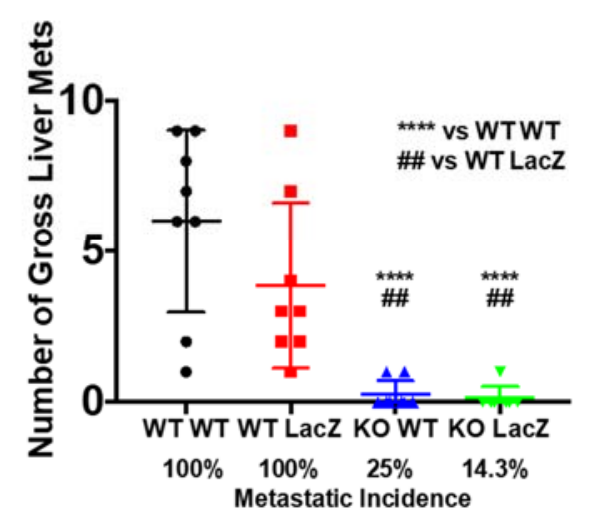

Figure 4. AXL expression on tumor cells is critical for PDA progression and metastasis.

A) AXL was ablated out using CRISPR-Cas9 in KPfC tumor cells. Cell lysates from WT and AXL KO KPfC cells were evaluated for indicated targets by western blot. B) Representative pictures of WT and AXL KO KPfC cells grown in $30 \%$ matrigel+ $+70 \%$ collagen for 4 days. C) WT and Ax/LacZ/LacZ C57BL/6 mice orthotopically injected with 250,000 cells/mouse WT and AXL KO $K P f C$ cells were enrolled in a survival study. Groups were as follows: WT KPfC cells in WT C57BL/6 mice ( $\mathrm{n}=8)$; WT KPfC cells in Axllacz/LacZ C57BL/6 mice $(\mathrm{n}=8)$; AXL KO KPfC cells in WT C57BL/6 mice ( $\mathrm{n=8}$ ); AXL KO KPfC cells in AxlLacZLacZ C57BL/6 mice ( $\mathrm{n=7})$. D) Number of gross liver metastases and metastatic incidence of the survival study in (C) are shown. ${ }^{* * * *} \mathrm{P}<$ 0.0001 vs WT KPfC cells in WT C57BL/6 mice; \#\# P $<0.01$ vs WT KPfC cells in Axlaczllacz C57BL/6 mice; by ANOVA. 


\section{Du et al Supplementary Figures and Legends}
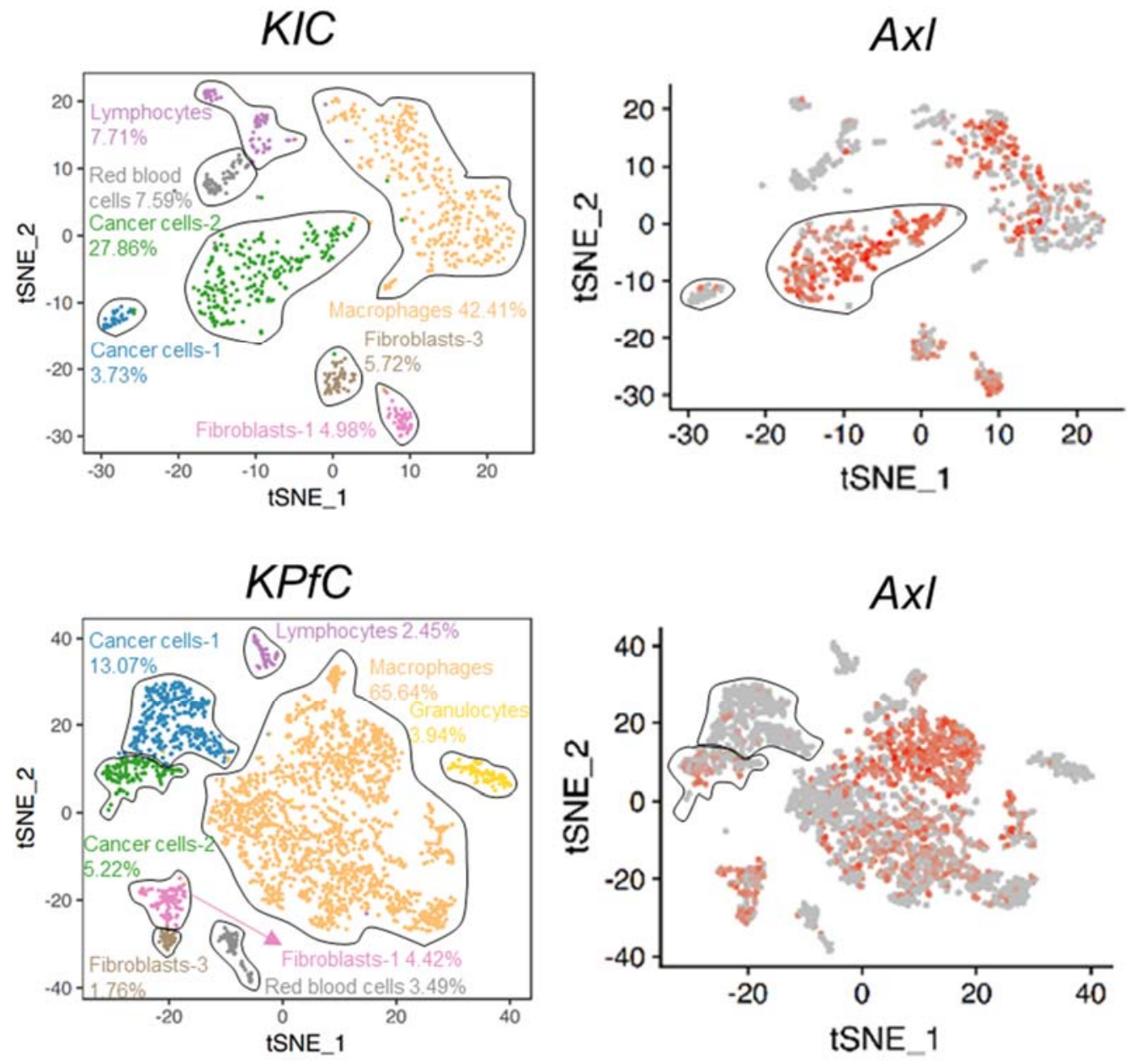

Supplementary Figure 1. ScRNA-Seq was performed with tumors harvested from KIC or KPfC mice. tSNE plots of $A x l$ expression for each cell population are shown. $A x l$ expression is highlighted in red in the second tSNE plot for each model. 
bioRxiv preprint doi: https://doi.org/10.1101/2020.07.06.190363; this version posted July 7, 2020. The copyright holder for this preprint (which was not certified by peer review) is the author/funder, who has granted bioRxiv a license to display the preprint in perpetuity. It is made available under aCC-BY-NC-ND 4.0 International license.

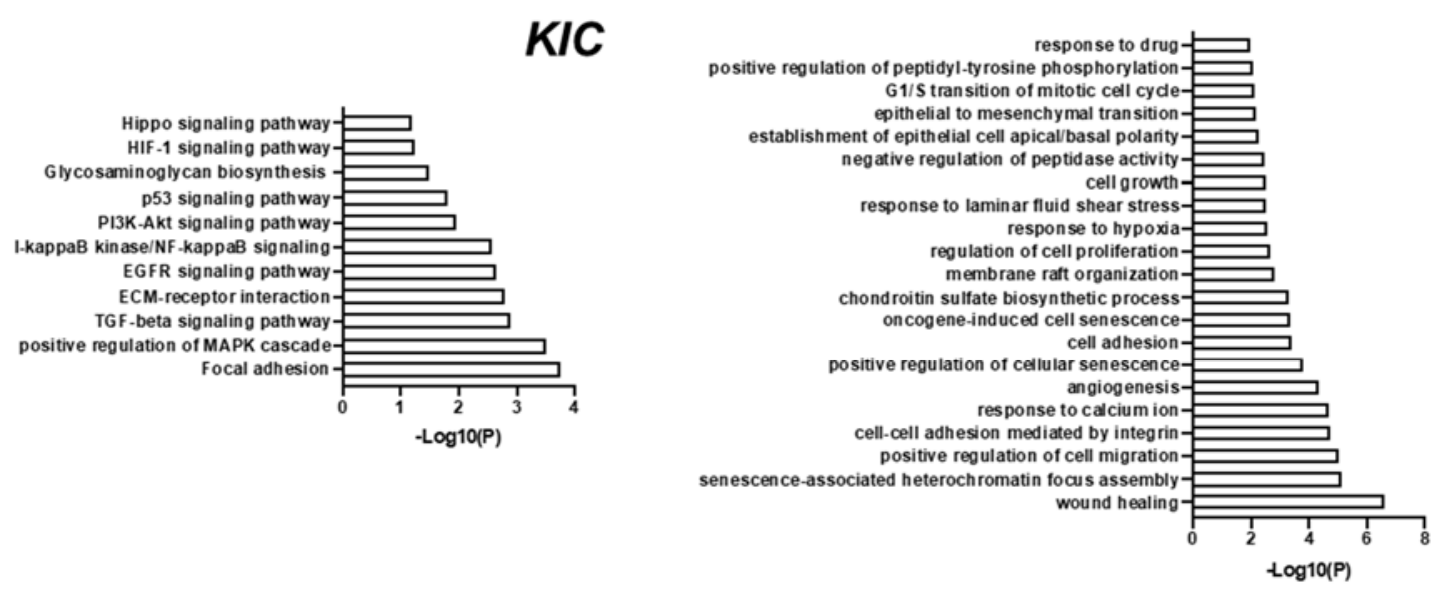

KPfC
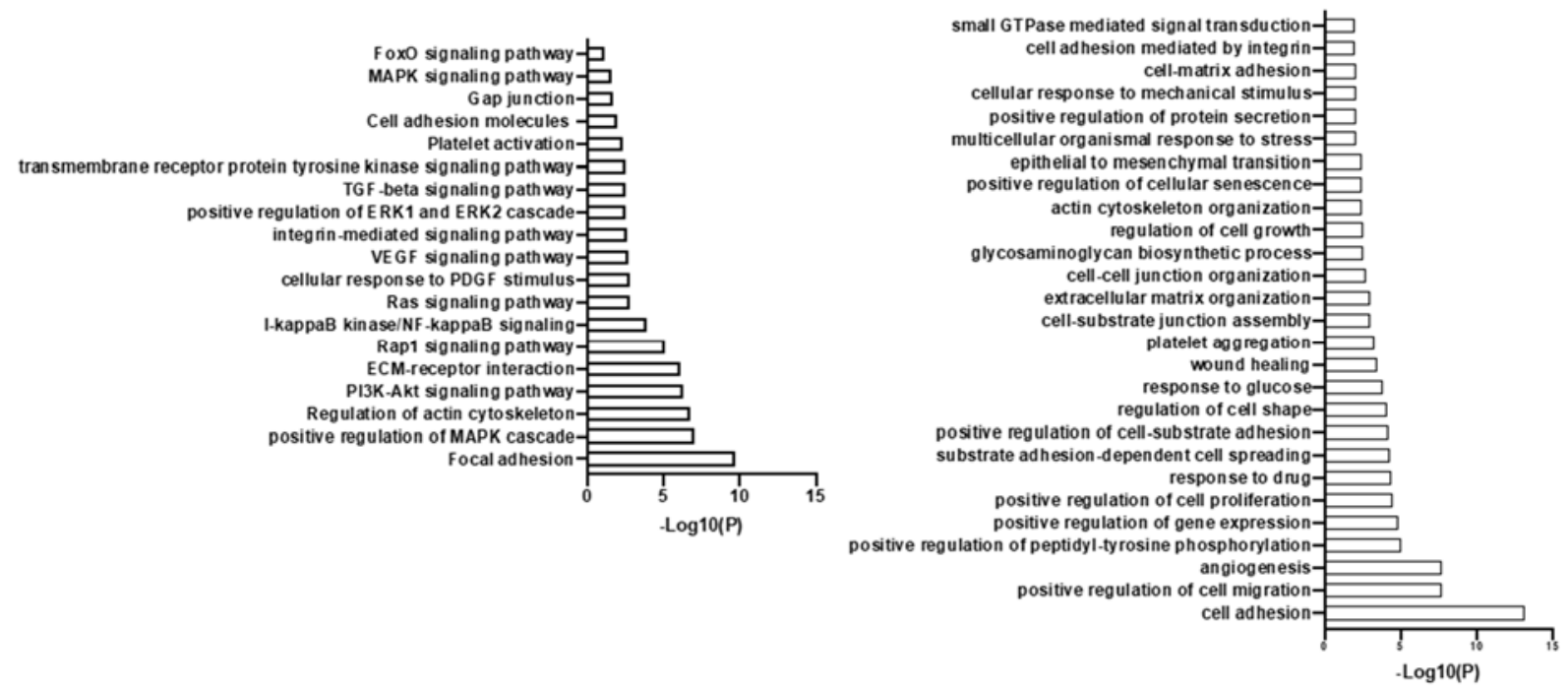

Supplementary Figure 2. Gene Ontology (GO) analysis of gene clusters from AXL-positive cancer cell populations based on scRNA-Seq data. 

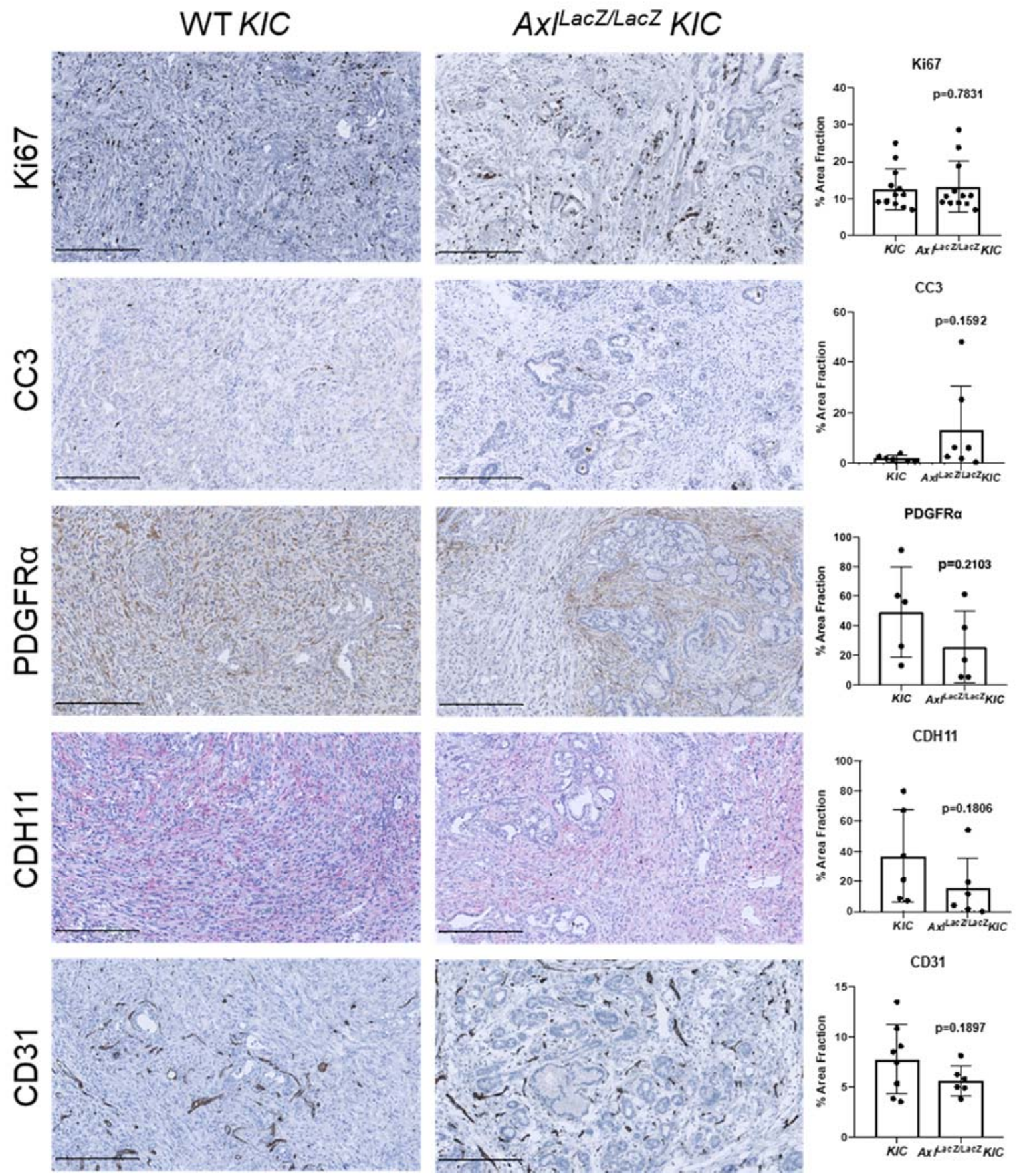

Supplementary Figure 3. Tumor tissues from KIC and AxlLacz/Lacz KIC mice were evaluated for indicated targets. Images were taken by Nanozoomer to cover the whole tissue and analyzed using ImageJ software. quantification of \% area fraction is shown. Each data point is the average of one sample. Data are displayed as mean \pm SD. $P$ values were generated by t-test. Scale bar, $250 \mu \mathrm{M}$. 

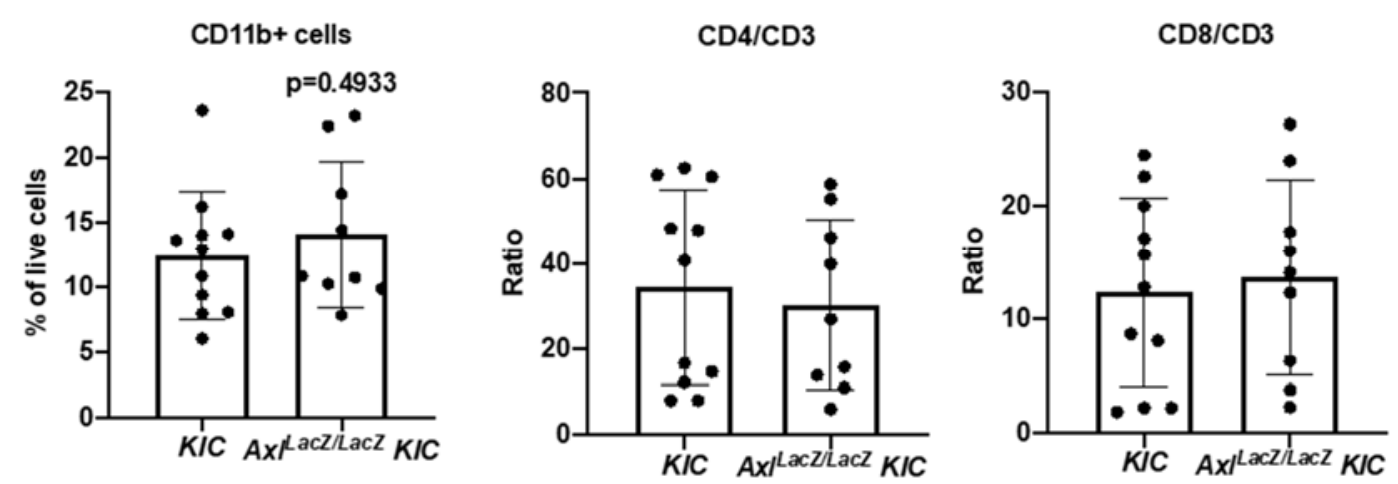

Supplementary Figure 4. Flow cytometry of tumor-associated myeloid and lymphoid cells from $K I C(n=11)$ and $A x /$ lacz/Lacz $K I C(n=9) . C D 11 b^{+}$myeloid cells, CD4/CD3, and CD8/CD3 ratio were analyzed. $P$ values were generated by $t$ test. 

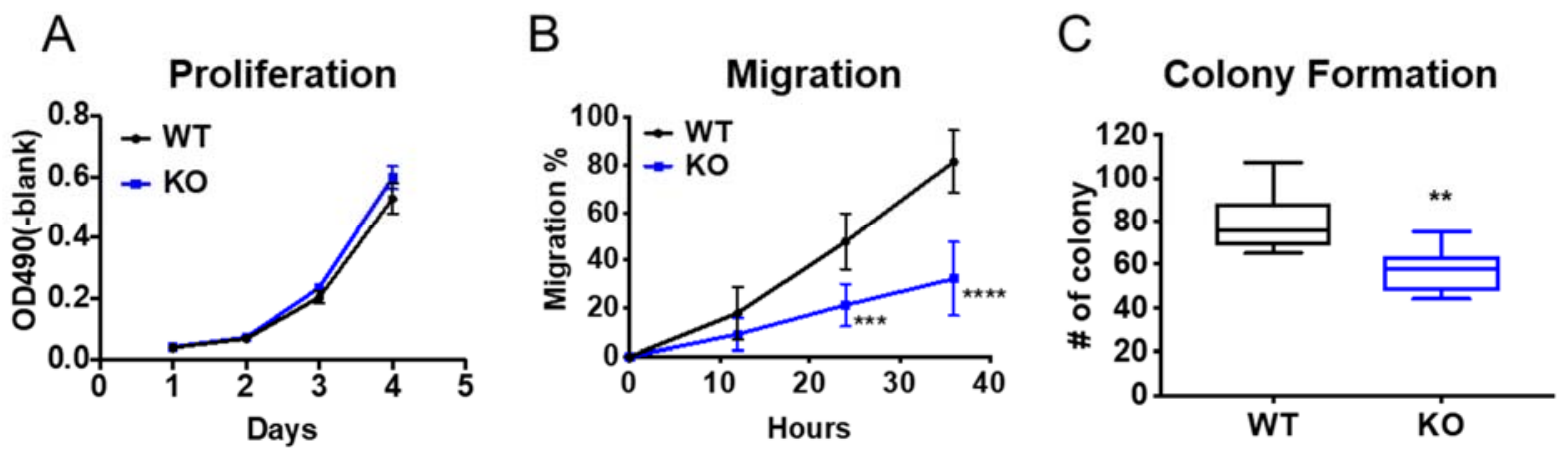

Supplementary Figure 5. A) Cell proliferation was investigated in three different WT and AXL KO KPfC cells using MTS assay with eight technical replicates. B) Cell migration was investigated in three different WT and AXL KO KPfC cells by a "scratch" assay with three technical replicates. Monolayers of the indicated cells were wounded with a pipet tip. The cells were incubated in $1 \%$ serum media. Wound closure was monitored at 12,24 , and 36 hours and is reported as $\%$ wound closure. ${ }^{* *} \mathrm{P}<0.001 ;{ }^{* * * *} \mathrm{P}<0.0001$; by t-test. C) Colony formation (colonies/hpf) for three different WT and AXL KO KPfC cells with three technical replicates is shown by box plot (min to $\max ) .{ }^{* *} \mathrm{P}<0.01$; by t-test. 


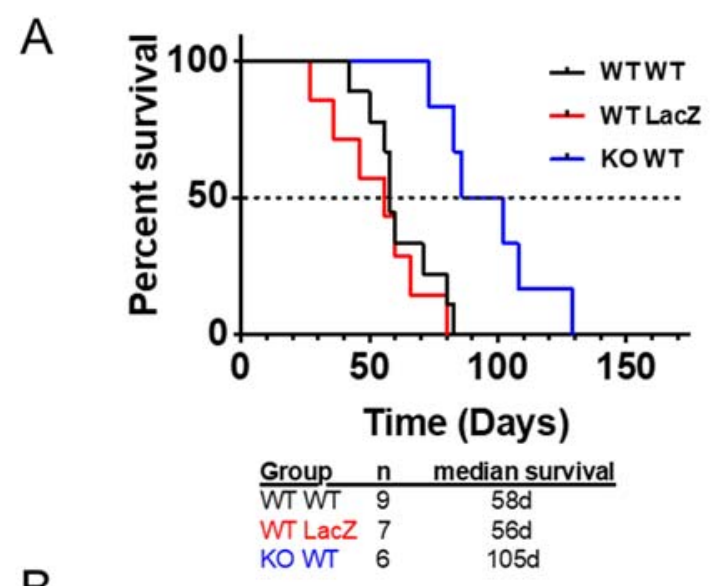

B

\begin{tabular}{cccc}
\hline Cell line & Mouse Background & Sample Number & Liver Mets \\
\hline WT Pan02 & WT C57BL/6 & 8 & $5 / 8(62.5 \%)$ \\
WT Pan02 & AxlLacZlLacZ C57BL/6 & 7 & $4 / 7(57.1 \%)$ \\
AXL KO Pan02 & WT C57BL/6 & 10 & $0 / 10(0 \%)$ \\
AXL KO Pan02 & AxlLacZlLacZ C57BL/6 & 9 & $0 / 9(0 \%)$ \\
\hline
\end{tabular}
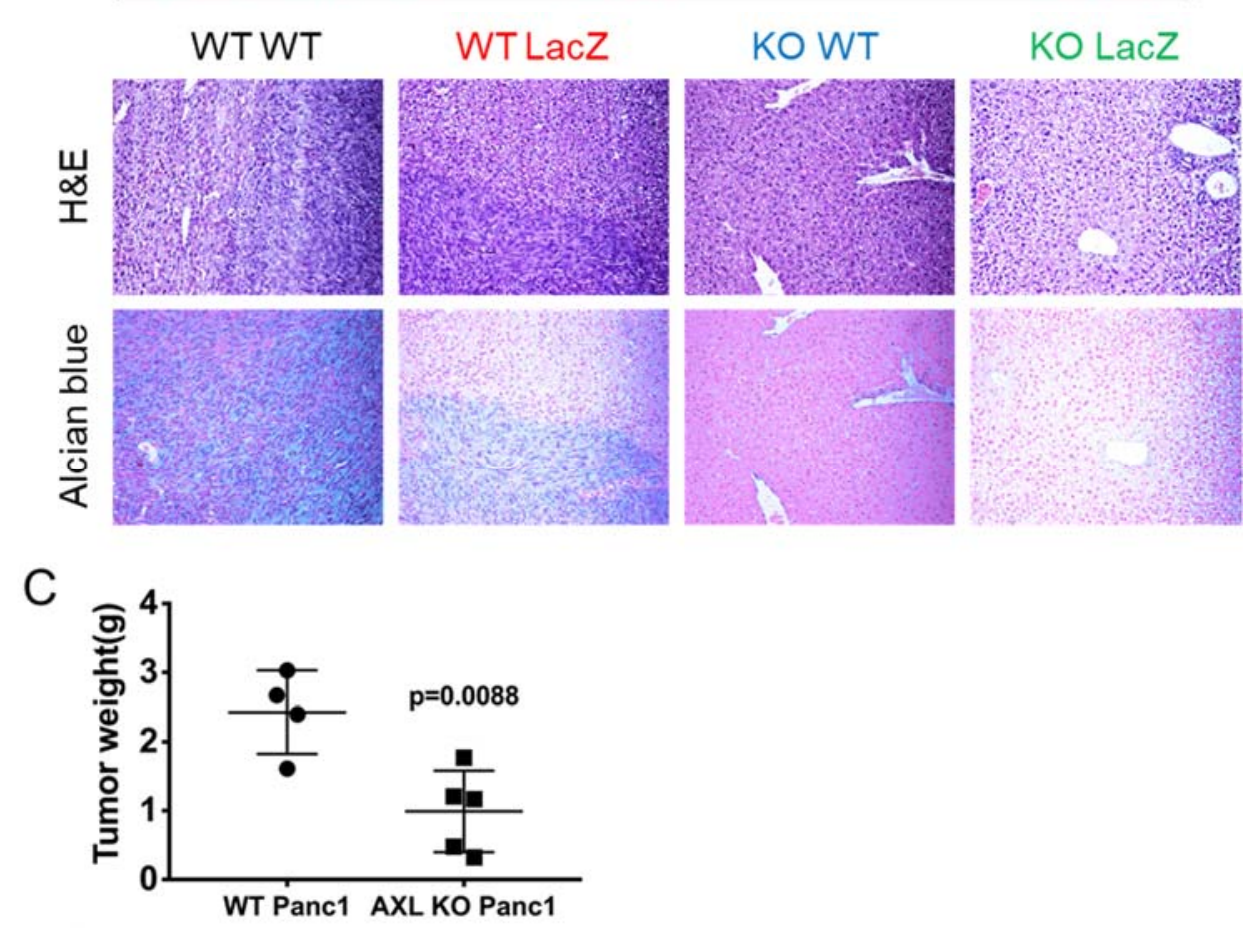

Supplementary Figure 6. A) WT and AxlLacZLacz C57BL/6 mice orthotopically injected with 500,000 cells/mouse WT and AXL KO Pan02 cells were enrolled in a survival study. Groups were as follows: WT Pan02 cells in WT C57BL/6 mice ( $\mathrm{n=9})$; WT KPfC cells in Ax/LacZLacz C57BL/6 mice $(n=7) ;$ AXL KO KPfC cells in WT C57BL/6 mice $(n=6)$. B) 500,000 cells/mouse WT and AXL KO 
Pan02 cells were splenically injected into WT and Ax/Lacz/Lacz C57BL/6 mice. Liver metastases were investigated 7 weeks after injection. Groups were as follows: WT Pan02 cells in WT C57BL/6 mice ( $\mathrm{n}=8$ ); WT KPfC cells in AxlLacZ/LacZ C57BL/6 mice ( $\mathrm{n=7}$ ); AXL KO KPfC cells in WT C57BL/6 mice ( $n=10)$; AXL KO KPfC cells in AxlLacz/Lacz C57BL/6 mice ( $n=9)$. H\&E and Alcian Blue stain were conducted in the liver tissues to confirm metastasis. Magnification, 10X. C) $1,000,000$ cells/mouse WT and AXL KO Panc1 cells were orthotopically injected into NON SCID mice. Tumor weight were investigated 11 weeks after injection. 